\title{
Illegitimate recombination in plants: a model for T-DNA integration
}

\author{
Godelieve Gheysen, Raimundo Villarroel, and Marc Van Montagu \\ Laboratorium voor Genetica, Rijksuniversiteit Gent, B-9000 Gent, Belgium
}

\begin{abstract}
Agrobacterium tumefaciens is a soil bacterium capable of transferring DNA (the T-DNA) to the genome of higher plants, where it is then stably integrated. Six T-DNA inserts and their corresponding preinsertion sites were cloned from Arabidopsis thaliana and analyzed. Two T-DNA integration events from Nicotiana tabacum were included in the analysis. Nucleotide sequence comparison of plant target sites before and after T-DNA integration showed that the T-DNA usually causes only a small (13-28 bp) deletion in the plant DNA, but larger target rearrangements can occur. Short homologies between the T-DNA ends and the target sites, as well as the presence of filler sequences at the junctions, indicate that T-DNA integration is mediated by illegitimate recombination and that these processes in plants are very analogous to events in mammalian cells. We propose a model for T-DNA integration on the basis of limited base-pairing for initial synapsis, followed by DNA repair at the junctions. Variations of the model can explain the formation of filler DNA at the junctions by polymerase slipping and template switching during DNA repair synthesis and the presence of larger plant target DNA rearrangements.
\end{abstract}

[Key Words: Agrobacterium tumefaciens; rearrangement; recombination; target; T-DNA; transgenic plants]

Received October 15, 1990; revised version accepted November 22, 1990.

Agrobacterium tumefaciens can infect most dicotyledonous plants at wounded sites, causing a neoplastic disease called crown gall. This transformation is the direct result of the transfer of a particular DNA segment, the T-DNA, from the bacterial tumor-inducing (Ti) plasmid to the plant nuclear genome, where the integration and expression result in the crown gall phenotype (for reviews, see Zambryski 1988; Gheysen et al. 1989). In contrast to transposons that can move repeatedly, the TDNA, once integrated, is stable. This reflects the fact that the T-DNA does not encode the products that mediate its movement. Some constitutively expressed genes of the A. tumefaciens chromosome are involved in bacterial attachment to plant cells, but most of the identified trans-acting proteins needed for T-DNA transfer are encoded by the virulence (vir) region, a segment on the Ti plasmid outside the T-DNA. Except for the virA gene, the other vir operons are induced in response to specific phenolic compounds excreted by wounded plant cells. The 24-bp direct repeats that flank the transferred DNA in the Ti plasmid are the only T-DNA sequences important for efficient mobilization to plants. These "border" sequences are functionally not equivalent; the right border repeat is absolutely required in cis for TDNA transfer, whereas the left repeat merely acts as a boundary beyond which DNA sequences are normally not transferred.

After nicking of both 24-bp repeats by the VirDl topoisomerase and VirD2 endonuclease protein complex, a linear single-stranded T-DNA (T-strand) is released by strand displacement DNA synthesis. This T-strand is considered the intermediate that is transferred from $A$. tumefaciens to the plant cells (Howard and Citovsky 1990). It is associated with proteins that would protect the DNA molecule from degradation during the whole transfer process (Dürrenberger et al. 1989). The VirE2 protein, which is a nonspecific single-stranded DNAbinding protein (Christie et al. 1988; Citovsky et al. 1988; Das 1988), would coat the length of the T-strand, whereas the VirD2 protein has been found to be covalently attached to the 5 ' end, that is, the right end, of the T-strand (Herrera-Estrella et al. 1988; Young and Nester 1988). The asymmetrical binding of the VirD2 protein to the right end of the T-strand and its possible function as a plant nucleus-targeting pilot protein (Herrera-Estrella et al. 1990) are consistent with the importance of the right border repeat in the T-DNA transfer process. The analogies between the $\mathrm{T}$-strand/protein complex formation and bacterial $\mathrm{F}$ plasmid conjugation have led to the formulation of a model for T-DNA transfer to plant cells (Zambryski 1988).

In contrast to the progress made in understanding the molecular events of the transfer process, we know little about the mechanism of T-DNA integration into the plant chromosomes. In situ hybridization (Ambros et al. 1986) and genetic mapping (Chyi et al. 1986) demonstrated that T-DNA insertions can occur in any chromosome. More recently, T-DNA tagging experiments have revealed preferential integration into transcriptionally active plant DNA loci (Koncz et al. 1989; Herman et al. 
1990). The ends of T-DNA inserts map within or nearby the 24 -bp repeats and are fused to different plant DNA sequences (Simpson et al. 1982; Yadav et al. 1982; Zambryski et al. 1982; Holsters et al. 1983; Kwok et al. 1985; Koncz et al. 1989). During this long period of analysis, only one integrated copy has been studied in detail (Gheysen et al. 1987), and more sequence data were necessary to generalize the conclusions drawn. In this paper we present data on six Arabidopsis thaliana DNA target sequences prior to and after T-DNA integration. We propose a general model for T-DNA integration that is based on illegitimate recombination in plants.

\section{Results}

Isolation of T-DNA clones from transgenic A. thaliana plants

A. thaliana transgenic lines were obtained after Agrobacterium-mediated leaf disc transformation using the T-DNA vectors pGSH1166 or pGSFR1161 (Fig. 1). One plant line of each transformation was retained for further analysis and cloning of the T-DNA insertions. The single T-DNA of the RUG-AT2 line was isolated from the RUG-AT2 genomic library (Materials and methods) using probe A (Fig. 1A) and was subcloned into pGem2 resulting in pAT2. Sequence analysis demonstrated that the RUG-AT2 T-DNA insertion has an intact right border but is truncated between the HindIII and Sall sites downstream from the hpt-coding sequence (Fig. 1A). The absence of the polyadenylation signal $\left(3^{\prime}\right.$ ocs $)$ does not have a significant effect on $h p t$ expression, probably because of fortuitous polyadenylation in the flanking plant DNA sequences (Dhaese et al. 1983; Ingelbrecht et al. 1989). The RUG-AT10 line transformed with the pGSFR1161 T-DNA (Fig. 1B) showed a complex Southern blot pattern when hybridized to probe B /data not shown). The RUG-AT10 genomic library was screened with probe $\mathrm{B}$, and a $6.5-\mathrm{kb}$ EcoRI fragment with an intact T-DNA insertion was subcloned into pGem2, resulting in PAT10.
To simplify the procedure of isolating T-DNA clones, transgenic $A$. thaliana plants were made that contained a bacterial kanamycin resistance $\left(\mathrm{Km}^{\mathrm{R}}\right)$ marker in the T-DNA (Fig. 1C). Cloning of DNA restriction fragments from these transgenic plants in the multicopy vector pGem2 allows selection of T-DNA clones in Escherichia coli on kanamycin-containing medium /see Materials and methods). T-DNA clones isolated from the lines RUG-AT3, RUG-AT4, and RUG-AT6 were named pAT3, pAT4, and pAT6, respectively. The two T-DNA insertions cloned from RUG-AT5 were named pAT5 and pAT5' (Table 1).

\section{Identification and cloning of T-DNA target sequences}

Hybridization of wild-type Arabidopsis DNA with flanking plant DNA from any of the isolated T-DNA clones revealed single fragments, indicating that all cloned T-DNAs had integrated in unique plant DNA (data not shown). The same probes were then used to isolate the plant targets from the genomic library (Materials and methods). Fragments containing the integration sites, as deduced from hybridization to left and/or right T-DNA :: plant junction probes, were subcloned from the purified phages into pGem2. These target clones were named pTT $X$ for T-DNA target and $\underline{X}$ corresponding to the number of the T-DNA clone (Table 1). Two additional target clones, obtained from Nicotiana tabacum, are also listed in Table 1; pTT1 has been analyzed previously (Gheysen et al. 1987), and pTT7 was isolated as described in Table 1.

\section{Sequence analysis of the T-DNA ends}

The sequence of all T-DNA :: plant junctions from the pAT clones (Table 1, column 4) was determined. Figure 2 shows the position of the T-DNA ends within the octopine Ti plasmid sequence. When the junction is at a position where the plant and T-DNA show one to several nucleotides of homology, a bracket indicates the region
Figure 1. Schematic representation of the T-DNA regions. pGSH1166, pGSFR1161, and pGVP246 are described in Van Lijsebettens et al. (1991\}. The T-DNA is flanked by the left (LB) and right $(\mathrm{RB})$ octopine border sequences. Only some restriction sites are indicated. $P_{1}$ and $P_{2}, P_{T R 1}{ }^{\prime}$ and $P_{T R 2}{ }^{\prime}$, dual promoters. (hpt) Hygromycin phosphotransferase; 3 'ocs, $3^{\prime}$ region of the octopine synthase; $(n p t I I)$ neomycin phosphotransferase II; (bar) phosphinothricin acetyltransferase; $\left(P_{n}\right.$ and $\left.3^{\prime} n\right)$ promoter and $3^{\prime}$ region of nopaline synthase, respectively; gene 2 encodes an indole acetamide hydrolase; $\left[\mathrm{Km}^{\mathrm{R}}\right.$ (Tn903)] kanamycin resistance gene from the transposon Tn903 (Oka et al. 1981). Bars under the maps represent fragments used as probes $A$ and $B$.

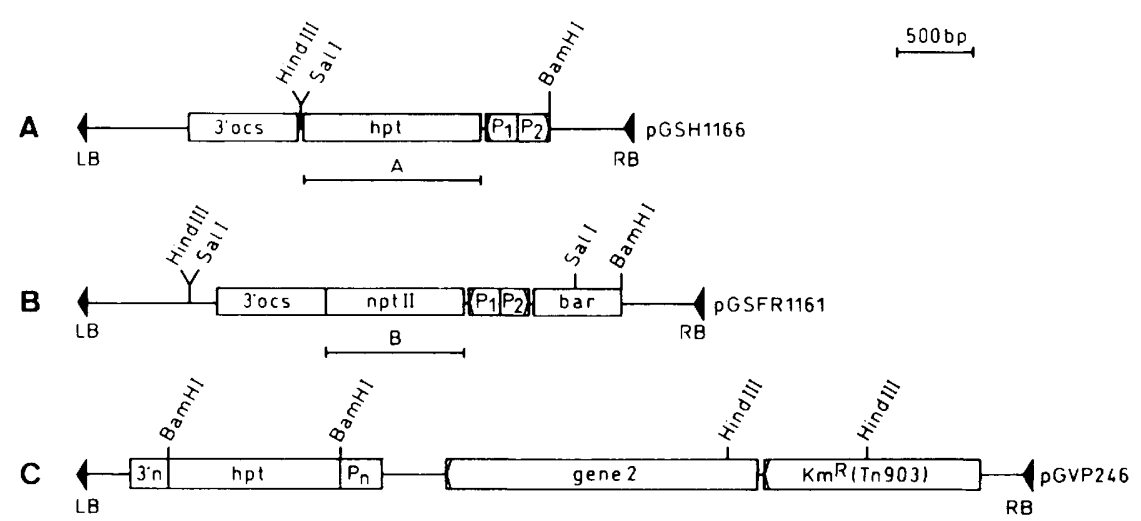


Table 1. Schematic overview of the isolated clones

\begin{tabular}{|c|c|c|c|c|}
\hline $\begin{array}{l}\text { Transgenic } \\
\text { A. thaliana }\end{array}$ & $\begin{array}{l}\text { T-DNA } \\
\text { construct }^{a}\end{array}$ & $\begin{array}{l}\text { T-DNA } \\
\text { copies }^{b}\end{array}$ & $\begin{array}{l}\text { T-DNA } \\
\text { clone }\end{array}$ & $\begin{array}{l}\text { Target } \\
\text { clone }\end{array}$ \\
\hline RUG-AT2 & pGSH1166 & 1 & pAT2 & pTT2 \\
\hline UG-AT10 & pGSFR1161 & $\geqslant 6$ & pAT10 & pTT10 \\
\hline RUG-AT3 & pGVP246 & 1 & pAT3 & pTT3 \\
\hline RUG-AT4 & pGVP246 & 1 & pAT4 & pTT4 \\
\hline RUG-AT5 & pGVP246 & $\geqslant 3$ & pAT5, pAT5' & pTT5 \\
\hline RUG-AT6 & pGVP246 & 2 & pAT6 & pTT6 \\
\hline $\begin{array}{l}\text { N. tabacum } \\
\text { tumors }\end{array}$ & $\begin{array}{l}\mathrm{Ti} \\
\quad \text { plasmid }\end{array}$ & \multicolumn{2}{|c|}{$\begin{array}{l}\text { T-DNA border } \\
\text { clones }\end{array}$} & \\
\hline W38C58-1 ${ }^{c}$ & pTiC58 & \multirow{2}{*}{\multicolumn{2}{|c|}{$\begin{array}{l}\operatorname{cg} 3\left\langle\left.\mathrm{RB}\right|^{\mathrm{c}}, \operatorname{cg} 4(\mathrm{LB})^{\mathrm{c}}\right. \\
\operatorname{cg} 101(\mathrm{LB})^{\mathrm{d}}\end{array}$}} & pTTl $^{\mathrm{e}}$ \\
\hline W38LGV21 ${ }^{\mathrm{d}}$ & pGV2206 & & & pTT $7^{\mathrm{f}}$ \\
\hline
\end{tabular}

(LB) Left T-DNA border; (RB) right T-DNA border.

${ }^{a}$ See Fig. 1.

${ }^{\mathrm{b}}$ As determined by Southern analysis.

c Zambryski et al. (1982).

${ }^{d}$ Holsters et al. (1983).

${ }^{\text {e }}$ Gheysen et al (1987).

${ }^{\mathrm{f}}$ Because cgl01 hybridized to a 1.7-kb EcoRI fragment from untransformed tobacco plants, pTT7 was isolated from the sublibrary with 1.2- to 2.5-kb EcoRI inserts as described in Gheysen et al. (1987). Attempts to identify the corresponding T-DNA RB in the W38LGV21 tumor using pTT7 as a probe were unsuccessful.

where the plant DNA and T-DNA must have joined. When the junction can be located unambiguously, an arrowhead is used. For comparison, other reported and some unpublished sequences are included in Figure 2; homologies between plant and T-DNA are not known in most cases, since the target sequences have not been isolated (except for ' $b^{\prime}$ and $d^{\prime}$, corresponding to the pTTl and pTT7 targets in Table 1). It is clear from these compiled data that the right T-DNA ends are clustered mainly around the first 3 nucleotides of the 24-bp repeat. At the left, T-DNA endpoints are spread over the 24-bp repeat. Some T-DNA junctions, left end as well as right end, are located internally to the 24 -bp repeats. Only one junction (indicated with $\mathrm{c}$ ) is outside of the place of the nick, but since the target of this T-DNA insertion has not been cloned, the GG nucleotides at the junction could be plant DNA.

\section{T-DNA integration is often accompanied by a small deletion in the plant DNA}

Physical mapping of T-DNA and target clones (data not shown/ indicated that T-DNA integration is usually not correlated with large rearrangements in the plant DNA. The sequence data in Figure 3, which are summarized in Table 2, show that in five of seven cases, T-DNA integration induced small target site deletions of 13-28 nucleotides.

The deleted sequences show patches of homology with the left and/or right T-DNA ends. Additional homolo- gies are found between plant DNA and T-DNA outside of the breakpoints, that is, in the T-DNA sequences that are deleted at the final junctions.

In addition to the 158-bp target (pTT1) duplication described previously (Gheysen et al. 1987), two newly analyzed T-DNA insertions were accompanied by larger target rearrangements. The pTT3 and pTT5 target clones, isolated using a left border probe, did not hybridize to the corresponding right border probes. This means
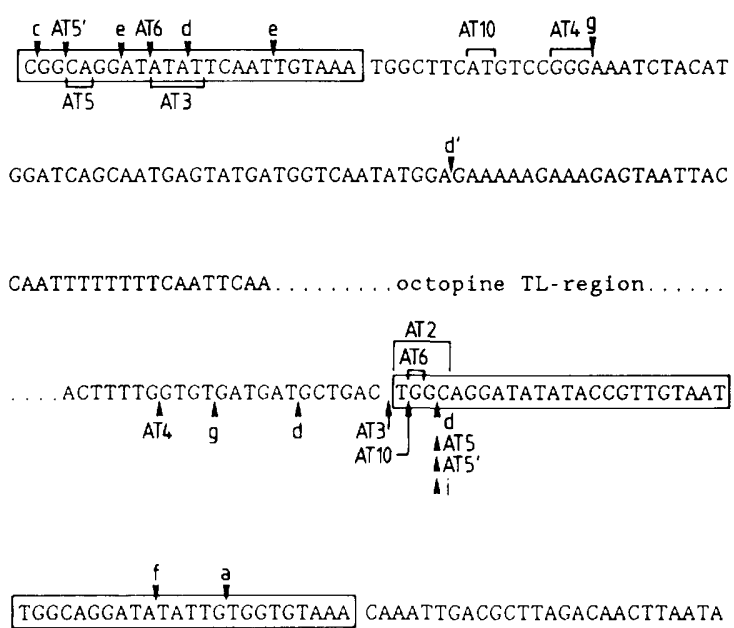

ACACATTGCGGACGTITTTAATGTACTGAATTCACATCCGTTTGATACTTGT

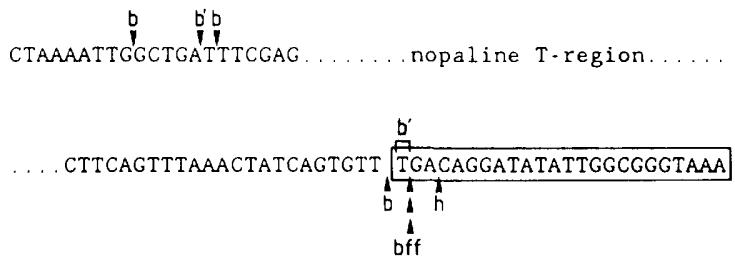

Figure 2. Endpoints of the T-DNA after integration in the plant genome. The T-DNAs from the nopaline and octopine $\mathrm{Ti}$ plasmids are shown from left to right, with the 24-bp repeats boxed. The repeats are defined according to Van Haaren et al. (1988). The nick generated in the bottom strand of the T-DNA occurs after the third nucleotide of the left and right repeats, and only sequences in between these nicks are normally transferred to the plant cell. Each arrowhead indicates the position of a sequenced T-DNA :: plant junction nearby or in the 24 -bp repeat. When the target sequence is known, either arrowheads or brackets are used. Brackets indicate homologies between the T-DNA border and the plant sequence; the sequence between brackets is present at the junction and can be of plant, T-DNA, or mixed origin. AT with a number refers to the T-DNA clones described in this work and summarized in Table 1. $(a)$ Yadav et al. (1982); $\left(b, b^{\prime}\right)$ Zambryski et al. (1982); $\left(b^{\prime}\right.$, corresponding to target pTT1; Gheysen et al. 1987); (c) Simpson et al. (1982); (d, $\left.d^{\prime}\right)$ Holsters et al. (1983) (d' corresponding to target pTT7); $(e)$ Kwok et al. (1985); $(f)$ Koncz et al. (1989); $(g)$ Gheysen et al. (1990); (h) G. Gheysen et al., unpubl. data of a T-DNA right border clone isolated from the $N$. tabacum W38T37:: Tn7-1 tumor (Holsters et al. 1982); (i) T-DNA insertion from $A$. thaliana RUG-AT50 (M. Van Lijsebettens, pers. comm.). 
Gheysen et al.

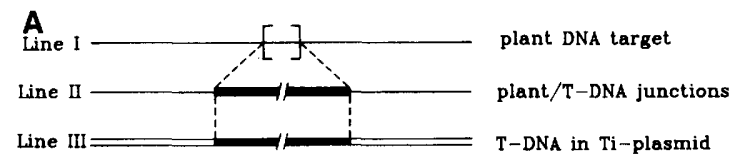

10

I

I I

I I I

3

I

I I

III

4

I

I I

II I

5

I

II I II

6

1

II

III

7

I

II

I I I

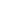

GTTACCÄG̊̊CCAGCCCCAACC

GTTACCAGCCCAGCCCAACC $\mid$ gcaggtcgacggatcgatcccggtc $-1 /$ gatgatgctgac $\mid$ TGGC $\mid$ GTCATCTTCT

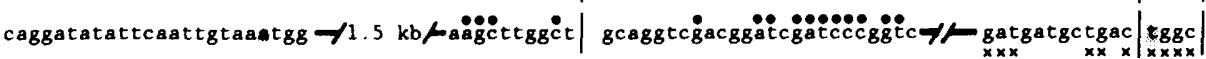

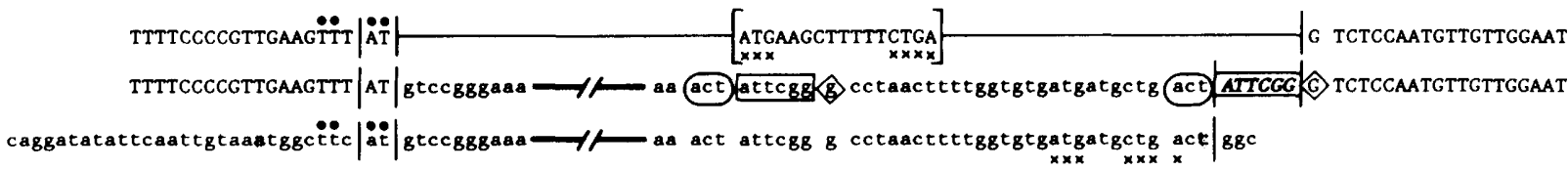

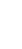

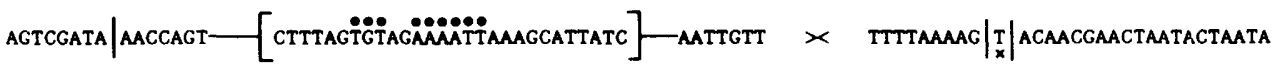
AGTCGATA |TACTGTACTTGTCGTATAMGAMCATATATTCT|tttcgag atcagtgtt|T|ACAACGAACTAATACTAATA

Figure 3. (See facing page for legend.) 
Table 2. Summary of characteristics at the T.DNA junctions

\begin{tabular}{|c|c|c|c|c|}
\hline \multirow[b]{2}{*}{$\begin{array}{l}\text { Target } \\
\text { clone }^{\mathrm{a}}\end{array}$} & \multirow{2}{*}{$\begin{array}{l}\text { Deletion of } \\
\text { target plant DNA } \\
\text { in nucleotides }\end{array}$} & \multicolumn{2}{|c|}{ Plant/T-DNA junctions } & \multirow[b]{2}{*}{$\begin{array}{l}\text { Model } \\
\text { (in Fig. 5) }\end{array}$} \\
\hline & & $\begin{array}{l}\text { LB } \\
\text { junction }\end{array}$ & $\begin{array}{l}\mathrm{RB} \\
\text { junction }\end{array}$ & \\
\hline pTT2 & 22 & - & $S(4)$ & A \\
\hline pTT10 & 16 & $S(2)$ & $F(6)$ & B2 \\
\hline pTT3 & $\mathrm{L}$ & $S(4)$ & ND & $\mathrm{C}$ \\
\hline pTT4 & 14 & $S(3)$ & $F(44)$ & B3 \\
\hline pTT5 & L & $S(2)$ & ND & \\
\hline pTT6 & 13 & $F(6)$ & $S(1)$ & $\mathrm{B} 2$ \\
\hline pTT1 & $28^{\mathrm{b}}$ & $F(33)$ & $S(1)$ & $\mathrm{B} 1, \mathrm{~B} 3, \mathrm{C}$ \\
\hline pTT7 & ND & $F(10)$ & ND & B4 \\
\hline
\end{tabular}

(L) The presence of a small deletion could not be determined because of a large target DNA rearrangement; $\langle$ S $\rangle$ identical nucleotides in plant DNA and T-DNA at the junction/the number is indicated in parenthesis), (F) filler DNA at the junction (size in nucleotides is given in parenthesis); (ND) not determined.

${ }^{a}$ As listed in the last column of Table 1.

b The T-DNA insertion in the pTT1 target is also accompanied by a 158-bp target duplication (Gheysen et al. 1987).

that the plant sequences flanking both ends of the $T$ DNA inserts in pAT3 and pAT5 are not adjacent to each other in the untransformed plant DNA. Southern hybridizations and polymerase chain reaction (PCR) analysis of the T-DNA insertion sites in the RUG-AT3, RUG-AT5, and untransformed Arabidopsis lines confirmed the target rearrangements to be present and not to be cloning artifacts. Because the pAT5 right border and the pTT5 target show common bands when used to probe Arabidopsis Southern blots (data not shown), the rearrangements cannot be larger than 1 to several kilobases. In the case of pAT3, the T-DNA insertion is most likely accompanied by a large $(>3 \mathrm{~kb})$ duplication of flanking plant DNA (data not shown).

No similarities can be found between the different target sequences. Several of them are AT rich $1>70 \%$ AT compared to the average AT content of $\sim 60 \%$ ), especially in the deleted stretches; however, other insertions, such as pAT2 and pAT4, are flanked by more GC-rich $(>50 \%$ GC) plant DNA.

\section{Inserted nucleotides (filler DNA) are common at the T-DNA junctions}

Many of the analyzed T-DNA insertions contained filler DNA at one of their junctions (Fig. 3; Table 2). This filler DNA consists of additional nucleotides different from the plant target and T-DNA sequences adjacent to the junctions. However, searches in more distal plant and T-DNA sequences revealed a possible origin for the filler DNAs (indicated in Fig. 3B with arrows or enclosing rectangles).

In pAT10, the 6 nucleotides at the right border are identical to a sequence 29 nucleotides internal in the T-DNA. pAT4 contains a 44-nucleotide-long filler at the right border, which is an inverted repetition of T-DNA sequences at the left border; this filler creates an extra Ncol site, which is indeed present in the RUG-AT4 transgenic plant (Southern analysis; data not shown). The 6 nucleotides at the left border of pAT6 are also found in the plant DNA 14 nucleotides from the junction. The 33-nucleotide filler at the left border in cg4 (target pTTl) is homologous to a sequence $>200$ bp farther in the plant target (Gheysen et al. 1987). The stretch of 10 nucleotides at the left border in cg101 (target pTT1) is partially homologous to a sequence in the Ti plasmid, 16 nucleotides to the left of the cgl01 breakpoint.

The generation of most of these filler sequences can be explained by polymerase slippage or template switching during repair of the gaps at the junctions (see Discussion; Fig. 5B, below).

\section{Discussion}

Most T-DNA endpoints are located in or nearby the 24-bp repeats

Seven T-DNA inserts were cloned from transgenic Arabidopsis plants, either by plaque hybridization or by selection in $E$. coli. Compared to the construction and

Figure 3. Sequence analysis of plant DNA target sites prior to and after T-DNA integration. $(A)$ Scheme of the DNA sequences presented in $B .|B|$ The numbers refer to the target clones as listed in Table 1 . The T-DNA :: plant junctions (second line) are compared with the original plant DNA (first line; uppercase) and the T-DNA sequences found in the Ti plasmid (third line; lowercase). The nucleotides deleted from the plant DNA are enclosed in brackets. The plant targets were sequenced for at least 200 bp in both directions from the T-DNA insertion site (GenBank and EMBL accession numbers M17371 and X56109-X56115, respectively). The thin horizontal line in the plant DNA indicates that the connected sequences are continuous in the target. The T-DNA is shown from the left to the right border, the inner ends of the 24-bp repeats are shaded and, when necessary, the distance to this repeat is indicated. Only T-DNA sequences that are normally transferred to the plant, i.e., inside the nicks, are shown, and the internal part of the T-DNA is indicated with a thick line. Identical nucleotide stretches in T-DNA and plant DNA are indicated by dots (LB and target) or crosses (RB and target). Junctions between the T-DNA and plant DNA are shown by vertical lines. When the junctions are at positions where the plant and T-DNA show one to several nucleotides of homology, two vertical lines delineate the region where plant DNA and T-DNA must have joined. Additional DNA at the junctions (filler sequences) are shown in bold italics. Arrows or rectangles indicate a possible origin of the filler sequences. In the case of duplication junctions, the same symbols |round, rectangle, diamond combination) are used as in Fig. 5B.2. The inverted 5-nucleotide homology in the pAT4 T-DNA left border to the plant target (see Discussion and Fig. 5B.3) is indicated with a line above the sequence. The tgt trinucleotides possibly involved in the polymerase slippage (see Discussion) are underlined. The large $\times$ symbol in the pTT1, pTT3, and pTT5 targets indicates that the sequences to the left and the right of the T-DNA are not adjacent plant DNA sequences. 
screening of a phage $\lambda$ library, cloning an enriched plant DNA fraction in a multicopy plasmid followed by electroporation allows more rapid isolation of plant DNA genomic clones. Indeed, a small-scale preparation of DNA from a single Arabidopsis plant is sufficient, and the same method has been used successfully to clone genes from Nicotiana plumbaginifolia by colony hybridization (D. Hérouart, pers. comm.). It is a valid alternative to the PCR, especially if relatively large genomic fragments have to be cloned.

Sequence analysis of the T-DNA :: plant junctions (Fig. 2) reveals that 10 of 14 of the T-DNA ends are located $<10$ nucleotides from the position of the border nick in Agrobacterium. Similar conservation of free DNA ends has also been found in extrachromosomally circularized SV 40 molecules in monkey cells: $97 \%$ of the junctions had lost $<15$ nucleotides of the input termini. However, there is a clear difference between the left and right T-DNA ends, the right being clustered around the first 3 nucleotides of the 24-bp repeat. The wellconserved right T-DNA end supports the hypothesis that the VirD2 protein attached to the $5^{\prime}$ end accompanies or even guides (Herrera-Estrella et al. 1988, 1990) the TDNA to the plant nucleus protecting the right border from degradation (Dürrenberger et al. 1989). Although the left T-DNA junctions show slightly more variation, all of them (except for the truncated T-DNA in pAT2) are located within $20 \mathrm{bp}$ from the left repeat. Only left endpoints $>250$ bp remote from the left repeat could be counterselected in our system. This indicates that left T-DNA ends located $50-250 \mathrm{bp}$ from the border repeat might not be as prevalent as reported earlier (Zambryski et al. 1982; Jorgensen et al. 1987).

\section{Illegitimate recombination in plants}

From the detailed study of eight T-DNA insertions, we can conclude that T-DNA integrates into plant chromosomes by processes that are analogous to illegitimate recombination events in mammalian cells.

First, sequence analysis of eight T-DNA target sites has shown little sequence similarity between different integration sites of the T-DNA into plant chromosomes. The absence of well-defined target requirements is typical of nonhomologous recombination processes such as those involved in integration of viral or transfected DNA in mammalian cells (for review, see Roth and Wilson 1988).

Characteristic of these processes is the presence of only small patches of homology at or nearby the junctions. Studies on the circularization of SV40 molecules in monkey cells has revealed that 1-6 complementary bases between single-stranded ends are sufficient for ligation directed by pairing of these homologies (Roth and Wilson 1986).

Another similarity with illegitimate recombination in mammalian cells is the presence of additional nucleotides at the recombinant junctions (Fig. 3; Table 2). About $10 \%$ of the junctions after SV40 circularization and of rearrangement junctions in nonimmune cells (compiled by Roth et al. 1989) contain 1-40 nucleotides of filler DNA. Of 13 T-DNA junctions, $5(38 \%)$ in our study contain filler DNAs. This high frequency might simply reflect the small sample size or it might be typical for (certain types or states of) plant cells, as Bakkeren et al. (1989) also reported filler DNA at $30-40 \%$ of the junctions from circularized extrachromosomal T-DNA molecules recovered from plants early after transfer.

Further analogies to illegitimate recombination events in mammalian cells are the generation of either a microdeletion or the presence of larger target rearrangements. Small deletions in the target have been reported for hepatitis B virus (HBV) integration studied in primary hepatocellular carcinomas (e.g., Hino et al. 1989) and during integration of transfected DNA in primary fibroblasts (Murnane et al. 1990). Larger target rearrangements are reviewed in Roth and Wilson (1988). Murnane et al. (1990) suggest that the difference between minor and major target rearrangements might be explained by differences in DNA recombination and stability in the different cell types studied.

Illegitimate recombination is basically a two-step process: DNA ends are first generated and then joined. For T-DNA integration, the ends of the T-DNA would be joined to plant chromosomal breaks. The T-DNA most likely enters the plant as a linear molecule (Zambryski 1988; Bakkeren et al. 1989), and although circularization can occur in the plant cell (Bakkeren et al. 1989), the substrate for integration is probably the linear form because the junctions to plant DNA are normally at or near the T-DNA ends (see Fig. 2). Only pAT4 has left border sequences linked to the right border, but since these sequences are complementary to the ones still present at the left junction, they cannot be derived from T-DNA circularization. Free ends within the plant DNA, which is the other substrate for the reaction, can be generated in a variety of ways such as errors during replication or repair, or nicks during exposure of single strands in transcription (Roth and Wilson 1988). Several enzymes involved in these processes, such as topoisomerases I and II, are known to nick or break DNA. There are indications that T-DNA would preferentially integrate in transcriptionally active regions (Koncz et al. 1989; Herman et al. 1990|. This could be explained by the higher likelihood of nicks in these regions, as well as the better accessibility of the target due to unraveling of the nucleosomes of transcribed DNA by comparison with tightly coiled, transcriptionally silent sequences (Patient and Allan 1989). Also, irradiation of plant cells, resulting in single-stranded breaks, results in higher integration rates of foreign DNA (Köhler et al. 1989).

\section{A model for T-DNA integration}

At present, there is no conclusive evidence whether the integrating T-DNA molecule is single or double stranded. If the T-DNA is transferred to the plant cell as a single-stranded DNA-protein complex, it must be converted into double-stranded DNA either before or during integration. Electroporation experiments into plant pro- 
toplasts suggest that single-stranded DNA can be rapidly converted into double-stranded DNA by plant enzymes (Rodenburg et al. 1989). However, the fact that singlestranded DNA results in a higher stable transformation frequency might indicate that single-stranded rather than double-stranded DNA is the preferred substrate of integration (Rodenburg et al. 1989). Most doublestranded DNA recombination models involve singlestranded overhangs after unwinding or exonucleolytic action (Lin et al. 1984), or invasion of D-loops by singlestranded DNA (e.g., Meselson and Radding 1975). Therefore, we will formulate a model for T-DNA integration emphasizing the single-stranded T-DNA ends, with the T-DNA body being either single or double stranded.

The model, as summarized in Figure 4, is a modified version of the preliminary model that has been suggested earlier (Gheysen et al. 1987). Besides the additional sequence data from more T-DNA insertions, we have also taken into account recent models proposed for $\mathrm{HBV}$ integration (Hino et al. 1989) and for insertion of a truncated LINE-1 element (Boccaccio et al. 1990). To keep the diagrams visually simple, T-DNA integration is shown at a nick that has become enlarged to a small gap by unwinding and $5^{\prime} \rightarrow 3^{\prime}$ exonuclease activity by host cell enzymes (step 1). Invasion of T-DNA could also be at nicks or breaks in a replication fork. The invading ends of the T-DNA would form a heteroduplex with the single-stranded target DNA in the gap (step 2). The small size of the final target deletion indicates that the ends of the T-strand are located close to one another at this time. This is symbolized by the "knot" in Figure 4, which is omitted in Figure 5 for simplicity. The overhangs of the T-DNA ends are nicked and removed, and the T-DNA is ligated to the target ends (step 3a). The finding that the right border is more exact could be due to protection by the covalently attached VirD2 protein but could also suggest a VirD2-supported integration in some cases (step 3b). Indeed, VirD2 could be a multifunctional enzyme such as the cistron A protein that is covalently attached to the $5^{\prime}$ end of $\phi \times 174$ and has been shown to participate in nicking and strand separation as well as ligation (Eisenberg et al. 1977). However, the transfer of the VirD2 protein, together with the T-strand to the plant nucleus, has yet to be proved. In any event, synthesis of the second strand of the T-DNA or repair of the gaps at the ends of a double-stranded T-DNA molecule is initiated by the introduction of a nick in the upper strand of the target providing a free $3^{\prime}$ end (step 4). The different steps of the integration model are not necessarily executed in the strict order stated above; for example, the left border could integrate first and second strand synthesis could start before the right border is ligated to the target.

\section{Variations on the model}

Because the integrations of the analyzed T-DNA insertions mostly differ from one another, by the variation in the structure of the T-DNA ends or in rearrangements of the target DNA, we will try to explain all integration
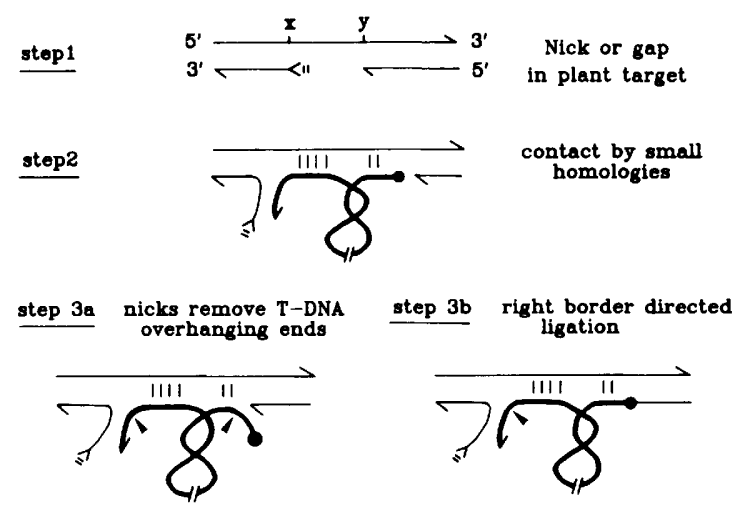

step 4 nick in upper strand and gap repair using the $T$-strand as template

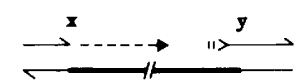

Note: The size of the small plant DNA deletion $(x-y)$ associated with $T-D N A$ integration depends on the $5^{\prime} 3^{\prime}$ exonuclease activity in step 1 and repair in steps $3 \& 4$

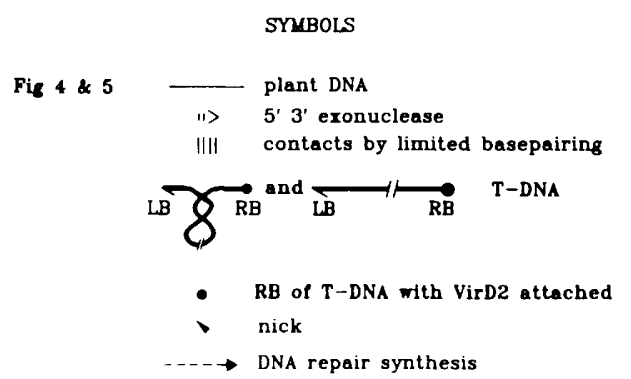

Figure 4. General model for T-DNA integration. Symbols are explained at the bottom. (Step 1) A nick in the target plant DNA can be generated in a variety of ways and can then be converted to a gap by a $5^{\prime} \rightarrow 3^{\prime}$ exonuclease. (Step 2) The T-strand invades the gap, and contacts between T-DNA ends and target are formed by partial pairing. The integrating T-DNA molecule could also be double stranded with single-stranded ends. (Step $3 a$ ) The overhangs of the T-DNA ends are nicked and removed and the T-strand is ligated to the target. (Step $3 b$ ) The right border (RB) could also be ligated with the help of the covalently linked VirD2 protein. The small homologies that promote initial pairing will either be present at the final junctions or deleted, depending on the location of the nicks. Repair on the free ends before ligation can generate filler DNA (see Fig. 5B). (Step 4) Synthesis of the second strand of the T-DNA is initiated by the introduction of a nick in the upper strand of the target followed by gap repair. If the T-DNA integrates as a doublestranded molecule, only the gaps at the T-DNA ends have to be repaired.

events by a modification of the general model in Figure 4. First, although the majority of T-DNA ends in the plant are close to the 24 -bp repeats, truncated T-DNAs missing either the left and/or right part occur with variable frequency (Gheysen et al. 1990). The short T-DNAs could be generated in the bacteria, could originate by breaks during or after transfer, or could be generated by the very mechanism of integration (Gheysen et al. 1990). 


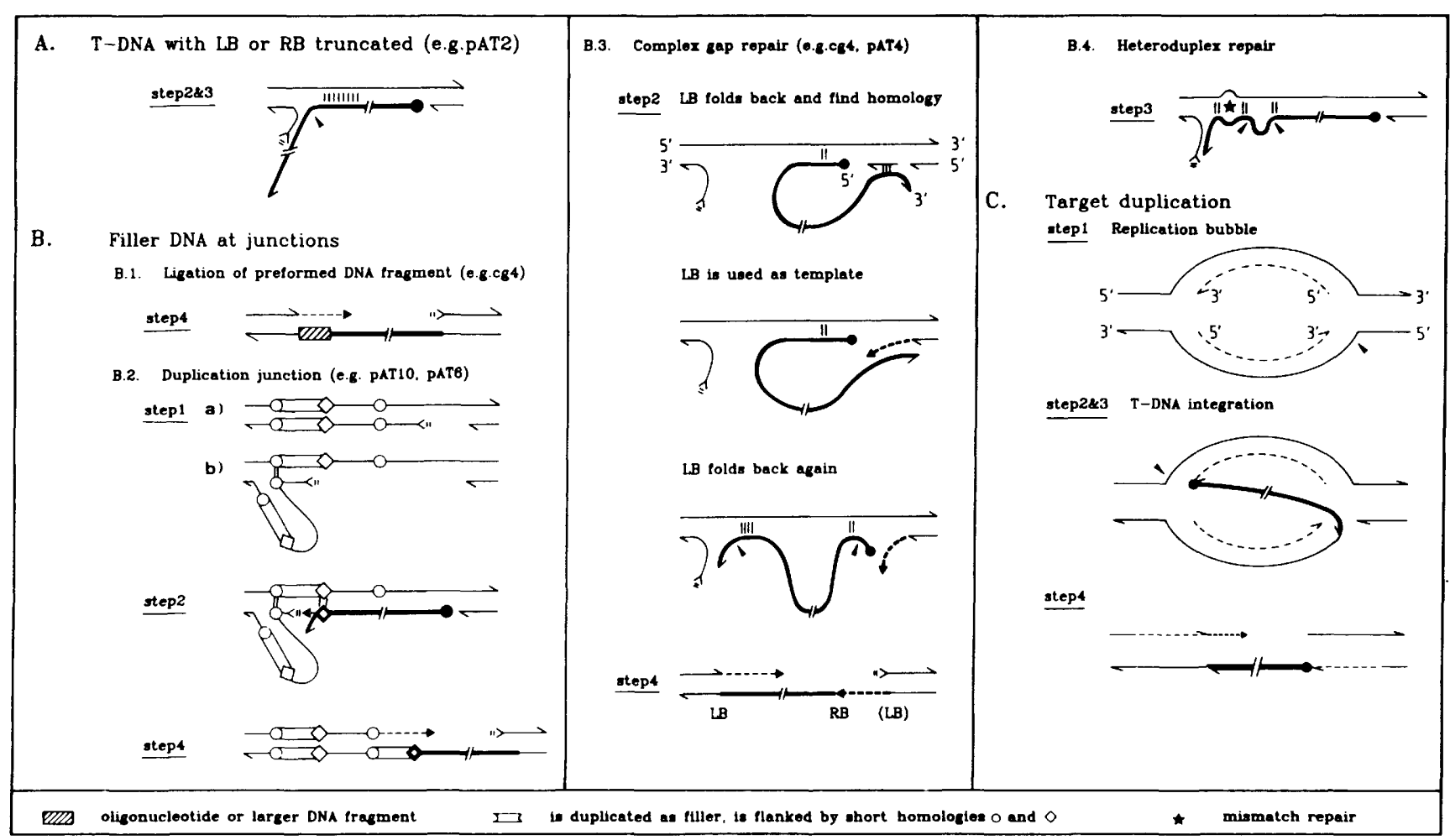

Figure 5. Variations on the model. For more details, see text. New symbols are explained at the bottom. For simplicity, the T-strand is shown as a stretched thick line instead of a knot (Fig. 4). Steps 1-4 are analogous to those in Fig. 4; only relevant steps are shown in each case. $|A|$ Truncated T-DNAs could be generated when homologies are found inside the T-DNA, rather than near the ends. $(B)$ Filler DNA can be generated in a variety of ways. (1) Capture of a preformed DNA fragment at the junction. (2) DNA located 5' of the junction can be used as template for end joining, resulting in a duplication junction. A small direct repeat (e.g., 3 nucleotides, $O$; step $1 a)$ in the target allows slipped mispairing (step $1 b)$. A sequence at the T-DNA end finds homology in the target $(\diamond$; step 2) and uses upper strand as template for gap repair of the bottom strand. The resulting heteroduplex is resolved by repair synthesis (step 4). (3) DNA distant from the junction can be used as template for gap repair. The inverted homology to the left border (LB) present at the right junction in pAT4 can be explained as follows. The LB folds back close to the right border (RB), finds homology, and is used as template for gap repair synthesis (step 2). The LB folds back again, the ends are processed, and the gaps are repaired (step 4). (4) Repair of heteroduplex at the junctions. A heteroduplex of plant DNA and T-DNA ends can be resolved by removal of single-stranded loops and mismatch repair. (C) Integration at a replication bubble generates a large target duplication flanking the T-DNA insertion.

The truncated left border in pAT2 could be an example of the last hypothesis. In analogy with L1 integration (Boccaccio et al. 1990), annealing of an internal T-DNA sequence to homologies in the plant target followed by repair processes could generate a truncated T-DNA copy (Fig. 5A).

As has been argued by Roth et al. (1989), filler DNA at recombinant junctions can be generated by a number of different mechanisms.

1. One source of filler DNA could be the addition of preformed blocks of nucleotides from elsewhere in the genome to broken ends (Fig. 5B.1). The size of the block could vary from a small oligonucleotide sequence (Roth et al. 1989) to an Okazaki fragment (up to $\sim 300 \mathrm{bp}$; Nicholls et al. 1987).

2. Several filler DNAs (e.g., pAT10 and pAT6) are part of a duplication junction, typically produced by slip/mispair/repair processes described by Roth et al. (1985). Terminal homologies of 1-2 nucleotides between tar- get and the invading T-strand (diamonds in Fig. 5B.2) would be enough to prime repair synthesis at the junctions after partial unwinding of the target. Slipmispairing (circles in Fig. 5B.2), followed by repair synthesis, leads to a small sequence duplication (rectangles in Fig. 5B.2).

3. The complex filler at the pAT4 right junction can be explained by a combination of polymerase slipping and template switching. The model in Figure $5 \mathrm{~B} .3$ is different from, but based on, the fold-back hypothesis of Papanicolaou and Ripley (1989). The left border folds back close to the right border, finds homology in the target (a candidate 5-nucleotide homology is indicated with a bracket above the sequence in Fig. 3), and is then used as a template for an abortive DNA synthesis. The left border folds back again, the ends are processed, and the gaps repaired. In reality, as can be seen in Figure 3, the filler DNA is still more complicated (indicated by the arrows) because a slip-mispair reaction of the polymerase should have occurred 
between the tgt repeats resulting in a duplication of 9 nucleotides.

4. The filler DNA at the cg4 left junction (target pTT1; Gheysen et al. 1987) might also be such a complex repair process using plant DNA as template, or could simply result from the insertion of a preformed fragment (Fig. 5B.1).

5. The filler DNA at the left border in cg101 (target pTT7) is partially a repetition of a sequence located in the Ti plasmid 16 nucleotides to the left of the TDNA junction. Because sequence data from the right border of this T-DNA insertion are not available, it is difficult to hypothesize an origin for the complete filler. However, mismatch repair of a heteroduplex between the AGCACTGCACA sequence of the target and the complement of AGCAATGAGTA from the T-DNA would explain the ATGAGTA part of the filler (Fig. 5B.4).

Characteristic of the T-DNA insertion in the pTT1 target (Gheysen et al. 1987) was a 158-bp plant DNA duplication flanking the T-DNA. Also the pAT3 T-DNA insertion is probably flanked by a large plant DNA duplication. A duplication of the target is possible when the T-DNA integrates at a staggered nick or when integration occurs at breakpoints between sister chromatids within a replication bubble (see Fig. $5 \mathrm{C}$ ), as postulated by Wilkie and Palmiter (1987). T-DNAs arranged in tandem or inverted repeats could be the consequence of end ligation of T-DNA copies before insertion, but the inverted repeats are more likely due to strand switching during repair at the T-DNA ends (Jorgensen et al. 1987).

The proposed model does not exclude the occurrence of other large chromosomal rearrangements, including large deletions or inversions of plant target DNA. These can happen when free plant DNA ends are fused to other plant DNA nicks before T-DNA invasion or during repair of the junctions. In conclusion, T-DNA integration seems to be a typical example of illegitimate recombination in plants with variations on a general model as a consequence of the versatile process of end joining and repair.

\section{Materials and methods}

Isolation and characterization of transgenic A. thaliana plants

Transgenic $A$. thaliana C24 plants were obtained from M. Van Lijsebettens (Van Lijsebettens et al. 1991). C24, T1, or T2 plants were grown in soil after germination in vitro. DNA was prepared from these plants as described by Dellaporta et al. (1983) for all Southern analyses and for cloning from the RUG-AT6 line and as described by Pruitt and Meyerowitz (1986) for all other cloning experiments. Southern hybridizations were performed as described previously (Gheysen et al. 1990). PCR was done as described by Saiki (1990).

\section{Construction and screening of phage $\lambda$ genomic libraries}

Genomic libraries were constructed from the RUG-AT2 and RUG-AT10 lines as described by Krebbers et al. (1988). The
RUG-AT2 genomic library, made from a pool of hemizygous and homozygous $\mathrm{T} 2$ plants, was used to clone all target plant DNA sequences described in this work. Plant DNA fragments flanking the T-DNA insertions at the left or right border were used as probes. About $10^{5}$ pfu were screened, and depending on the probe, 3-15 target candidates hybridized, except for probes from pAT5' that gave no positive plaques in repeated screenings. Positive phages were purified and different DNA digests from minipreparation (Kao et al. 1982) were analyzed by hybridization to several probes.

Electroporation and selection in $\mathrm{E}$. coli of recombinant plasmids containing A. thaliana T-DNA inserts

A size fraction of digested plant DNA (150-350 ng) was ligated to $0.1-1 \mu \mathrm{g}$ pGem2 (Promega), cut with HincII or XbaI, and dephosphorylated. On the basis of Southern analysis of the TDNA inserts, the following digests and size fractions were used: RUG-AT3 HpaI ( $\sim 16 \mathrm{~kb})$, RUG-AT4 XbaI ( $\sim 10 \mathrm{~kb})$, RUG-AT5 $X b a I(7-20 \mathrm{~kb})$, and RUG-AT6 XbaI $(8-12 \mathrm{~kb}$ and $\sim 20 \mathrm{~kb})$. DNA was isolated from $0.8 \%$ agarose gels by centrifugal filtration (Zhu et al. 1985). The ligations were phenolized, precipitated, resuspended in $10 \mu \mathrm{l} \mathrm{H}_{2} \mathrm{O}$, and dialyzed on VSWP01300 filters (Millipore) against distilled water. If necessary, the volume was decreased by Speedvac centrifugation.

Electroporation in the E. coli strain MCl061/Casadaban and Cohen 1980) was performed using the Gene Pulser apparatus from Bio-Rad according to the manufacturer's advice, resulting in $1 \times 10^{5}$ to $5 \times 10^{5}$ triacillin-resistant clones. By selection of the total transformation mixture on $25 \mu \mathrm{g} / \mathrm{ml}$ of kanamycin, 3-79 $\mathrm{Km}^{\mathrm{R}}$ colonies were obtained, depending on the experiment. The $\mathrm{Km}^{\mathrm{R}}$ colonies were characterized by restriction and Southern analysis.

Plant DNA from a minipreparation on only 2 grams of plant material was used to clone the T-DNA insert|s| from the RUGAT6 line. Of the $55 \mathrm{Km}^{\mathrm{R}}$ clones obtained from RUG-AT6, 12 were analyzed; 9 had a $10-\mathrm{kb} X b a I$ insert (pAT6) and the other 3 were contaminants.

\section{Subcloning and sequencing}

Restriction fragments containing T-DNA junctions or target plant DNA were identified by Southern analysis and subcloned in pGem 2 for sequencing by the dideoxy method (Sanger et al. 1977). When fragments were too large to sequence completely using the SP6 and T7 primers, oligonucleotide primers were designed to continue sequencing.

\section{Acknowledgments}

We thank Jan Gielen for help with sequencing, Peter Breyne and Marcelle Holsters for providing the pGVP246 vector and the T37 :: Tn7 T-DNA clone, respectively, and Mieke Van Lijsebettens and Didier Hérouart for communication of unpublished results. Allan Caplan, Alfredo Herrera-Estrella, Marcelle Holsters, Ann Depicker, and Mieke Van Lijsebettens are sincerely acknowledged for critical reading of the manuscript, and Martine De Cock, Karel Spruyt, Vera Vermaercke, and Stefaan Van Gijsegem, for preparing it. This research was supported by grants from the Services of the Prime Minister (I.U.A.P. 120C0187) and Vlaams Actieprogramma Biotechnologie (174KP490).

The publication costs of this article were defrayed in part by payment of page charges. This article must therefore be hereby 
marked "advertisement" in accordance with 18 USC section 1734 solely to indicate this fact.

\section{References}

Ambros, P.F., A.J.M. Matzke, and M.A. Matzke. 1986. Localization of Agrobacterium rhizogenes T-DNA in plant chromosomes by in situ hybridization. EMBO /. 5: 2073-2077.

Bakkeren, G., Z. Koukolíková-Nicola, N. Grimsley, and B. Hohn. 1989. Recovery of Agrobacterium tumefaciens TDNA molecules from whole plants early after transfer. Cell 57: 847-857.

Boccaccio, C., J. Deschatrette, and M. Meunier-Rotival. 1990. Empty and occupied insertion site of the truncated LINE-1 repeat located in the mouse serum albumin-encoding gene. Gene 88: 181-186.

Casadaban, M.J. and S.N. Cohen. 1980. Analysis of gene control signals by DNA fusion and cloning in Escherichia coli. $J$. Mol. Biol. 138: 179-207.

Christie, P.J., J.E. Ward, S.C. Winans, and E.W. Nester. 1988. The Agrobacterium tumefaciens virE2 gene product is a single-stranded-DNA-binding protein that associates with $T$ DNA. J. Bacteriol. 170: 2659-2667.

Chyi, Y.S., R.A. Jorgensen, D. Goldstein, S.D. Tanksley, and F. Loaiza-Figueroa. 1986. Locations and stability of Agrobacterium-mediated T-DNA insertions in the Lycopersicon genome. Mol. Gen. Genet. 204: 64-69.

Citovsky, V., G. De Vos, and P. Zambryski. 1988. Singlestranded DNA binding protein encoded by the virE locus of Agrobacterium tumefaciens. Science 240: 501-504.

Das, A. 1988. Agrobacterium tumefaciens virE operon encodes a single-stranded DNA-binding protein. Proc. Natl. Acad. Sci. 85: 2909-2913.

Dellaporta, S.L., J. Wood, and J.B. Hicks. 1983. A plant DNA minipreparation: Version II. Plant Mol. Biol. Reporter 1: 1921.

Dhaese, P., H. De Greve, J. Giclen, J. Seurinck, M. Van Montagu, and J. Schell. 1983. Identification of sequences involved in the polyadenylation of higher plant nuclear transcripts using Agrobacterium T-DNA genes as models. EMBO I. 2: 419-426.

Dürrenberger, F., A. Crameri, B. Hohn, and Z. KoukolíkováNicola. 1989. Covalently bound VirD2 protein of Agrobacterium tumefaciens protects the T-DNA from exonucleolytic degradation. Proc. Natl. Acad. Sci. 86: 9154-9158.

Eisenberg, S., J. Griffith, and A. Kornberg. 1977. $\$$ X174 cistron $A$ protein is a multifunctional enzyme in DNA replication. Proc. Natl. Acad. Sci. 74: 3198-3202.

Gheysen, G., M. Van Montagu, and P. Zambryski. 1987. Integration of Agrobacterium tumefaciens transfer DNA (TDNA) involves rearrangements of target plant DNA sequences. Proc. Natl. Acad. Sci. 84: 6169-6173.

Gheysen, G., L. Herman, P. Breyne, M. Van Montagu, and A. Depicker. 1989. Agrobacterium tumefaciens as a tool for the genetic transformation of plants. In Genetic transformation and expression (ed. L.O. Butler, C. Harwood, and B.E.B. Moseley), pp. 151-174. Intercept, Andover.

Gheysen, G., L. Herman, P. Breyne, J. Gielen, M. Van Montagu, and A. Depicker. 1990. Cloning and sequence analysis of truncated T-DNA inserts from Nicotiana tabacum. Gene 94: 155-163.

Herman, L., A. Jacobs, M. Van Montagu, and A. Depicker. 1990. Plant chromosome/marker gene fusion assay to study normal and truncated T-DNA integration events. Mol. Gen. Genet. 224: 248-256.
Herrera-Estrella, A., Z.-M. Chen, M. Van Montagu, and K. Wang. 1988. VirD proteins of Agrobacterium tumefaciens are required for the formation of a covalent DNA-protein complex at the $5^{\prime}$ terminus of T-strand molecules. EMBO $J$. 7: 4055-4062.

Herrera-Estrella, A., M. Van Montagu, and K. Wang. 1990. The Agrobacterium VirD2 polypeptide directs $\beta$-galactosidase into tobacco nuclei. Proc. Natl. Acad. Sci. (in press).

Hino, O., K. Ohtake, and C.E. Rogler. 1989. Features of two hepatitis $B$ virus (HBV) DNA integrations suggest mechanisms of HBV integration. I. Virol. 63: 2638-2643.

Holsters, M., R. Villarroel, M. Van Montagu, and J. Schell. 1982. The use of selectable markers for the isolation of plantDNA/T-DNA junction fragments in a cosmid vector. Mol. Gen. Genet. 185: 283-289.

Holsters, M., R. Villarroel, J. Gielen, J. Seurinck, H. De Greve, M. Van Montagu, and J. Schell. 1983. An analysis of the boundaries of the octopine TL-DNA in tumors induced by Agrobacterium tumefaciens. Mol. Gen. Genet. 190: 35-41.

Howard, E. and V. Citovsky. 1990. The emerging structure of the Agrobacterium T-DNA transfer complex. BioEssays 12: $103-108$.

Ingelbrecht, I.L.W., L.M.F. Herman, R.A. Dekeyser, M.C. Van Montagu, and A.G. Depicker. 1989. Different 3' end regions strongly influence the level of gene expression in plant cells. Plant Cell 1: 671-680.

Jorgensen, R., C. Snyder, and J.D.G. Jones. 1987. T-DNA is organized predominantly in inverted repeat structures in plants transformed with Agrobacterium tumefaciens C58. Mol. Gen. Genet. 207: 471-477.

Kao, F.-T., J.A. Hartz, M.L. Law, and J.N. Davidson. 1982. Isolation and chromosomal localization of unique DNA sequences from a human genomic library. Proc. Natl. Acad. Sci. 79: 865-869.

Köhler, F., G. Cardon, M. Pöhlman, R. Gill, and O. Schieder. 1989. Enhancement of transformation rates in higher plants by low-dose irradiation: Are DNA repair systems involved in the incorporation of exogenous DNA into the plant genome? Plant Mol. Biol. 12: 189-199.

Koncz, C., N. Martini, R. Mayerhofer, Z. Koncz-Kalman, H. Körber, G.P. Redei, and J. Schell. 1989. High-frequency TDNA-mediated gene tagging in plants. Proc. Natl. Acad. Sci. 86: 8467-8471.

Krebbers, E., L. Herdies, A. De Clercq, J. Seurinck, J. Leemans, J. Van Damme, M. Segura, G. Gheysen, M. Van Montagu, and I. Vandekerckhove. 1988. Determination of the processing sites of an Arabidopsis $2 \mathrm{~S}$ albumin and characterization of the complete gene family. Plant Physiol. 87: 859-866.

Kwok, W.W., E.W. Nester, and M.P. Gordon. 1985. Unusual plasmid DNA organization in an octopine crown gall tumor. Nucleic Acids Res. 13: 459-471.

Lin, F.-L., K. Sperle, and N. Sternberg. 1984. Model for homologous recombination during transfer of DNA into mouse $\mathrm{L}$ cells: Role for DNA ends in the recombination process. Mol. Cell. Biol. 4: 1020-1034.

Meselson, M.S. and C.M. Radding. 1975. A general model for genetic recombination. Proc. Natl. Acad. Sci. 72: 358-361.

Murnane, J.P., M.J. Yezzi, and B.R. Young. 1990. Recombination events during integration of transfected DNA into normal human cells. Nucleic Acids Res. 18: 2733-2738.

Nicholls, R.D., N. Fischel-Ghodsian, and D.R. Higgs. 1987. Recombination at the human $\alpha$-globin gene cluster: Sequence features and topological constraints. Cell 49: 369-378.

Oka, A., H. Sugisaki, and M. Takanami. 1981. Nucleotide sequence of the kanamycin resistance transposon Tn903. $J$. Mol. Biol. 147: 217-226. 
Papanicolaou, C. and L.S. Ripley. 1989. Polymerase-specific differences in the DNA intermediates of frameshift mutagenesis. In vitro synthesis errors of Escherichia coli DNA polymerase I and its large fragment derivative. I. Mol. Biol. 207: 335-353.

Patient, R.K. and J. Allan. 1989. Active chromatin. Curr. Opin. Cell Biol. 1: 454-459.

Pruitt, R.E. and E.M. Meyerowitz. 1986. Characterization of the genome of Arabidopsis thaliana. J. Mol. Biol. 187: 169-183.

Rodenburg, K.W., M.J.A. de Groot, R.A. Schilperoort, and P.J.J. Hooykaas. 1989. Single-stranded DNA used as an efficient new vehicle for transformation of plant protoplasts. Plant Mol. Biol. 13: 711-719.

Roth, D.B. and J.H. Wilson. 1986. Nonhomologous recombination in mammalian cells: Role for short sequence homologies in the joining reaction. Mol. Cell. Biol. 6: 4295-4304.

. 1988. Illegitimate recombination in mammalian cells. In Genetic recombination (ed. R. Kucherlapati and G.R. Smith), pp. 621-653. American Society for Microbiology, Washington.

Roth, D.B., T.N. Porter, and J.H. Wilson. 1985. Mechanisms of nonhomologous recombination in mammalian cells. Mol. Cell. Biol. 5: 2599-2607.

Roth, D.B., W.-B. Chang, and J.H. Wilson. 1989. Comparison of filler DNA at immune, nonimmune, and oncogenic rearrangements suggests multiple mechanisms of formation. Mol. Cell. Biol. 9: 3049-3057.

Saiki, R.K. 1990. Amplification of genomic DNA. In PCR protocols: A guide to methods and applications (ed. M.A. Innis, D.H. Gelfand, J.J. Sninsky, and T.J. White), pp. 13-20. Academic Press, San Diego.

Sanger, F., S. Nicklen, and A.R. Coulson. 1977. DNA sequencing with chain-terminating inhibitors. Proc. Natl. Acad. Sci. 74: 5463-5467.

Simpson, R.B., P.J. O'Hara, W. Kwok, A.L. Montoya, C. Lichtenstein, M.P. Gordon, and E.W. Nester. 1982. DNA from the A6S/2 crown gall tumors contains scrambled Ti-plasmid sequences near its junctions with the plant DNA. Cell 29: 1005-1014.

Van Haaren, M.J.J., N.J.A. Sedee, M. Krul, R.A. Schilperoort, and P.J.J. Hooykaas. 1988. Function of heterologous and pseudo border repeats in $\mathrm{T}$ region transfer via the octopine virulence system of Agrobacterium tumefaciens. Plant Mol. Biol. 11: 773-781.

Van Lijsebettens, M., R. Vanderhaeghen, and M. Van Montagu. 1991. Insertional mutagenesis in Arabidopsis thaliana: Isolation of a T-DNA-linked mutation that alters leaf morphology. Theor. Appl. Genet. (in press).

Wilkie, T.M. and R.D. Palmiter. 1987. Analysis of the integrant in MyK-103 transgenic mice in which males fail to transmit the integrant. Mol. Cell. Biol. 7: 1646-1655.

Yadav, N.S., J. Vanderleyden, D.R. Bennett, W.M. Barnes, and M.-D. Chilton. 1982. Short direct repeats flank the T-DNA on a nopaline Ti plasmid. Proc. Natl. Acad. Sci. 79: 63226326.

Young, C. and E.W. Nester. 1988. Association of the VirD2 protein with the $5^{\prime}$ end of $\mathrm{T}$ strands in Agrobacterium tumefaciens. /. Bacteriol. 170: 3367-3374.

Zambryski, P. 1988. Basic processes underlying Agrobacteriummediated DNA transfer to plant cells. Annu. Rev. Genet. 22: 1-30.

Zambryski, P., A. Depicker, K. Kruger, and H. Goodman. 1982. Tumor induction of Agrobacterium tumefaciens: Analysis of the boundaries of T-DNA. I. Mol. Appl. Genet. 1: 361370.

Zhu, J., W. Kempenaers, D. Van Der Straeten, R. Contreras, and
W. Fiers. 1985. A method for fast and pure DNA elution from agarose gels by centrifugal filtration. Bio/Technology 3: 1014-1016. 


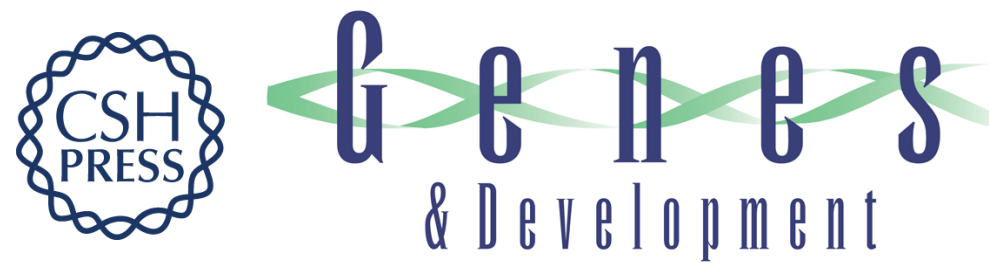

\section{Illegitimate recombination in plants: a model for T-DNA integration.}

G Gheysen, R Villarroel and M Van Montagu

Genes Dev. 1991, 5:

Access the most recent version at doi:10.1101/gad.5.2.287

References This article cites 48 articles, 19 of which can be accessed free at:

http://genesdev.cshlp.org/content/5/2/287.full.html\#ref-list-1

\section{License}

Email Alerting

Receive free email alerts when new articles cite this article - sign up in the box at the top Service right corner of the article or click here.

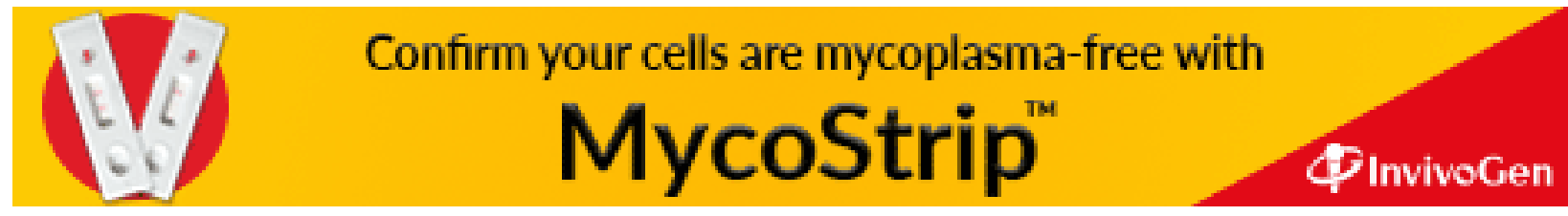

